\title{
The International Conference on Residency Education
}

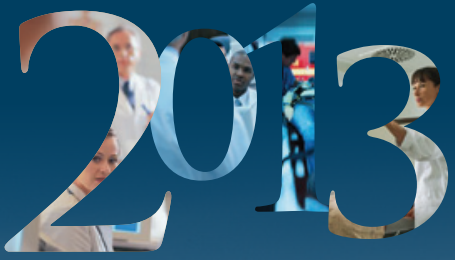

Educational Outcomes: Inspiring Residents, Improving Care
September 26-28, 2013

Calgary, Canada

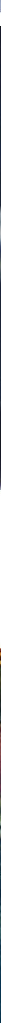

- New: International panel discussing top program director tips and techniques

- Learn new skills and best practices for enhancing teaching and assessment

- Examine competency-based medical education from a practical level

- Review education techniques, innovations and research conducted worldwide www.royalcollege.ca/icre | icre@royalcollege.ca (B) \& вLо 